\title{
Relationship between Language Learners' Attitudes toward Cultural Instruction and Pragmatic Comprehension and Production
}

\author{
Vahid Rafieyan \\ International College of Liberal Arts, Yamanashi Gakuin University, Kofu, Yamanashi, Japan \\ E-mail: rafieyanv@ygu.ac.jp
}

Doi:10.7575/aiac.alls.v.7n.4p.68

Received: 06/03/2016

URL: http://dx.doi.org/10.7575/aiac.alls.v.7n.4p.68

Accepted: 05/05/2016

\begin{abstract}
Development of target language pragmatic competence in language learners requires not only provision of cultural features of target language community in language classes but also language learner's willingness to learn and use those cultural features. To investigate the relationship between language learners' attitudes toward cultural instruction and their gains in comprehension and production aspects of pragmatic competence, the current study was conducted on 50 undergraduate Japanese students of English education at a university in Japan. The adapted version of the attitude questionnaire developed by Albirini (2009) was used to measure language learners' attitudes toward cultural instruction. A 24-item pragmatic comprehension test developed by Taguchi $(2007,2008)$ was used to measure language learners' pragmatic comprehension ability. Finally, a 32-item discourse completion task developed by Bardovi-Harlig (2009) was used to measure language learners' pragmatic production ability. The analysis of Pearson product-moment correlation coefficient (r) revealed a strong positive relationship between attitude toward cultural instruction and pragmatic comprehension ability as well as attitude toward cultural instruction and pragmatic production ability. The pedagogical implications of the findings suggested incorporation of interesting cultural features of the target language community in language classes and presenting them in interesting ways to attract language learners' attention and interest.
\end{abstract}

Keywords: Attitude, Cultural Instruction, Pragmatic Comprehension, Pragmatic Production

\section{Introduction}

Pragmatic competence, defined as the ability to convey one's intention appropriately and to interpret another's intention, explicitly or implicitly stated, in a communicative situation (Thomas, 1995), should be paid as equal attention in English language classes as grammatical competence. The reason is that, according to Bachman's (1990) model of communicative competence, pragmatic competence and grammatical competence are two distinct aspects of communicative competence. Thus, a high level of grammatical competence does not lead to a high level of pragmatic competence and even language learners at the advanced levels of language proficiency cannot achieve a native-like communicative competence (Bardovi-Harlig \& Dornyei, 1998; Bardovi-Harlig, 2001; Barron, 2003; Liu, 2006; Rose, 2005; Gharaghani et al., 2011). However, as understanding culture specific expressions of the target language requires directing language learners' attention to the cultural features of the target language, mere provision of cultural features of target language community in class instruction cannot develop language learners' pragmatic competence (Kasper \& Rose, 2002) rather language learners' interests to notice those cultural features plays an important role in the development of their pragmatic competence (Rafieyan et al., 2013b). Therefore, not only provision of cultural features of target language community in language classes but also language learner's willingness to learn those cultural features and to use them in intercultural interactions are the key factors to determine language learners' level of pragmatic competence (Ran, 2007).

The issue of language learners' attitudes toward incorporation of target language cultural features into class instruction has been investigated by a number of scholars in the field of linguistics. In one of these studies, Albirini (2009) explored language learners' attitudes toward the incorporation of cultural components of the target language community into their Arabic language course. Participants of the study were 32 students attending an Arabic course at the intermediate level at a university in the United States. Cultural materials introduced in the course consisted of videos, short stories, live TV news, songs, and guest speakers. Data were collected through a 21-item likert scale questionnaire measuring students' affective, cognitive, and behavioral attitudes toward learning target language cultural features. The findings of the study suggested that participants had positive attitudes toward cultural components of the target language community in their Arabic language course. The positive attitude was evident within the affective, cognitive, and behavioral domains. In another study, Saricoban and Caliskan (2011) investigated language learners' positive or negative attitudes toward learning the cultural features of the target language community. Participants in their study consisted of 95 students of English as a foreign language studying at a university in Turkey with an intermediate level of language proficiency. Data were collected through a 13-item multiple-choice questionnaire in which students' thoughts on the inclusion or 
exclusion of the cultural elements of the target language community in their language classrooms were examined. The findings of the study revealed the positive attitudes of language learners toward learning the cultural elements of the target language community. Rafieyan et al. (2013a) were the other researchers who investigated Iranian English as foreign language learners' affective, cognitive, and behavioral attitudes toward incorporating cultural features of the United States into their English instruction. Participants of the study consisted of 47 adult intermediate-level Iranian learners of English at a language institute in Iran. Data were collected through a likert scale attitude questionnaire comprising three subscales: affective, cognitive, and behavioral following a semester-long cultural intervention. The study found that language learners had an overall positive attitude toward the incorporation of cultural components into their classroom instruction. This positive attitude was evident within their affective, behavioral, and more significantly cognitive attitudes. Dweik and Al-sayyed (2015) also explored the attitudes of Jordanian students and teachers toward learning and teaching British culture presented in English as foreign language textbooks. Participants were 156 students and 30 language teachers at schools in Jordan. Data were collected through two likert scale questionnaires, one assessing students' attitudes and the other one assessing teachers' attitudes. The findings of the study indicated that both students and teachers had positive attitudes toward incorporation of British culture in English language classes.

The studies conducted so far have mostly investigated language learners' attitudes toward incorporation of target language cultural components into language classes. There is, however, a dearth of research to determine whether a positive attitude toward cultural instruction results in higher target language pragmatic competence or not. Therefore, considering the significant role of possessing a high level of pragmatic competence for successful cross-cultural communication on one hand and the significance of language learners' positive attitudes toward learning target language cultural features to develop their pragmatic competence on the other hand, the current study seeks to investigate the relationship between language learners' attitudes toward cultural instruction and their level of pragmatic competence comprising both comprehension and production aspects of pragmatic competence. Therefore, the research questions to be addressed in the current study are:

Is there a significant relationship between language learners' attitudes toward cultural instruction and their pragmatic comprehension ability?

Is there a significant relationship between language learners' attitudes toward cultural instruction and their pragmatic production ability?

Accordingly the null hypotheses are:

There is no significant relationship between language learners' attitudes toward cultural instruction and their pragmatic comprehension ability.

There is no significant relationship between language learners' attitudes toward cultural instruction and their pragmatic production ability.

\section{Methodology}

\subsection{Participants}

Participants of the study consisted of 50 Japanese students at a university in Japan. They were all undergraduate students of English education. The participant group consisted of 10 sophomores, 28 juniors, and 12 seniors. Their ages ranged from 19 to 21 with an average age of 20.2. Thirty-eight of them were females and the remaining twelve were males. Also, based on an English proficiency test administered before study to select participants of equal level of language proficiency, they were all among those being placed at the upper-intermediate level of language proficiency; therefore, they possessed an equally high level of language proficiency.

\subsection{Instruments}

To measure language learners' attitudes toward cultural instruction, an attitude questionnaire used in a study previously conducted by Albirini (2009) was adopted and modified according to the purpose of the study. The modified version of the questionnaire consisted of 12 items about participants' attitudes toward the cultural parts of the course. All items of the questionnaire were based on a 5-point likert scale ranging from 'strongly disagree' to 'strongly agree' with values 1 to 5 assigned to them respectively. In this respect, the value of 1 was assigned to 'strongly disagree', the value of 2 was assigned to 'disagree', the value of 3 was assigned to 'neutral', the value of 4 was assigned to 'agree', and the value of 5 was assigned to 'strongly agree'. The questionnaire consisted of the three subscales of affective (4 items), cognitive (4 items), and behavioral (4 items) attitudes. These three constructs referred respectively to language learners' emotional reaction to the cultural components of the course, their fact-based thoughts regarding the cultural components of the course, and their overt behavior directed toward the cultural components of the course (Zimbardo et al., 1977).

To measure language learners' pragmatic comprehension ability, a 24-item pragmatic comprehension test adopted from previous studies conducted by Taguchi $(2007,2008)$ was used. For each item there was a dialogue between a male and a female native English speaker. The last sentence in each dialogue contained an implied opinion which was intended to test language learners' ability to comprehend the speaker's implied intention. Each dialogue was followed by a yes/no question to check participants' comprehension of the speaker's intention. Language learners had to listen to each dialogue and answer the following question by writing yes or no.

To measure language learners' pragmatic production ability, a discourse completion task eliciting a variety of speech acts including expressions of gratitude, apologies, warnings, leave-takings, requests, condolences, declining offers, acceptance of a request, acceptance of an invitation, invitation, declining an invitation, an agreement, deflecting thanks, 
and an introduction developed by Bardovi-Harlig (2009) was adopted. The discourse completion task consisted of 32 scenarios comprising both initiating and responding scenarios. The initiating scenarios $(n=13)$ required language learners to initiate an interaction and the responding scenarios $(n=19)$ required language learners to respond to an interlocutor's turn.

\subsection{Procedure}

Starting from the beginning of the fall semester in the academic year 2015, cultural features of the United States were incorporated into four main language courses in which language learners participating in the study were enrolled. Around 10 minutes of each session was allocated to familiarizing language learners with the cultural features of the United States. Instructors explained various aspects of the United States' culture such as holidays, festivals, and food as well as culture specific ways of communication such as greetings, apologizing, and giving excuses. They also elicited comparisons between cultural features of the United States and language learners' heritage culture. At the end of the semester following a semester-long cultural instruction, the attitude questionnaire was distributed among language learners participating in the study. Language learners were asked to reflect on the idea mentioned for each item on the questionnaire and circle the number on the scale which best represented their opinion toward the idea mentioned. Following the competition of the attitude questionnaire, Pragmatic comprehension and production tests were administered to all students participating in the study. At the end, all questionnaire and test slips were collected for the purpose of data analysis.

\subsection{Data Analysis}

To measure language learners' attitudes toward cultural instruction, descriptive statistics were used to describe and summarize the properties of the data collected from the participants. Descriptive statistics consisted mainly of mean, standard deviation, and frequency percentages. The attitude toward the cultural features was represented by a mean score on a 5-point scale, where 1 (strongly disagree) represented the minimum score on the scale and 5 (strongly agree) represented the maximum score on the scale. The mean score, standard deviation, and frequency percentages were computed for each subscale of the attitude questionnaire including affective, cognitive, and behavioral attitudes individually as well as all subscales in general. As a mean score of 3 represented the neutral attitude toward cultural components of the course, a mean score of above 3 represented a positive attitude toward cultural components of the course whereas a mean score of below 3 represented a negative attitude toward cultural components of the course.

To assess language learners' pragmatic comprehension ability, 1 mark was allocated to each appropriate answer whereas no marks were allocated to inappropriate answers. As there were 24 items on the pragmatic comprehension test, each language learner could get a mark ranging from 0 to 24. In this regard, language learners who obtained a mark of between 0 and 6 (the fourth quarter of the total from the top) were considered at the poor level of pragmatic comprehension, language learners who obtained a mark of between 7 and 12 (the third quarter of the total from the top) were considered at the weak level of pragmatic comprehension, language learners who obtained a mark of between 13 and 18 (the second quarter of the total from the top) were considered at the strong level of pragmatic comprehension, and language learners who obtained a mark of between 19 and 24 (the first quarter of the total from the top) were considered at the optimal level of pragmatic comprehension.

To assess language learners' pragmatic production ability, the appropriateness of the responses to the discourse completion task was assessed by two native speakers of English using a four-point rating scale ranging from zero (cannot evaluate) to three (native-like). The ratings along with the description for each band on the scale have been provided in Table 1. As there were 32 scenarios, each participant could get a mark ranging from 0 to 96 . In this respect, language learners who obtained a mark of 0 were placed at the level of 'cannot evaluate', language learners who obtained a mark between 1 and 32 (the last third of the total from the top) were placed at the level of 'obviously off', language learners who obtained a mark between 33 and 64 (the second third of the total from the top) were placed at the level of 'slightly off, but acceptable', and language learners who obtained a mark between 65 and 96 (the first third of the total from the top) were placed at the level of 'native-like'.

Table 1. Description of Ratings for Pragmatic Production Ability

\begin{tabular}{lll}
\hline Rating & Band & Descriptions \\
\hline 3 & Native-like & $\begin{array}{l}\text { The utterance is almost perfectly appropriate. This is what a native speaker } \\
\text { would usually say in the situation }\end{array}$ \\
\hline 2 & Slightly off, but acceptable & $\begin{array}{l}\text { The utterance is a little off from native-like due to minor grammatical and } \\
\text { lexical errors but overall acceptable }\end{array}$ \\
\hline 1 & Obviously off & $\begin{array}{l}\text { The utterance is clearly non-native like because of strange, non-typical way } \\
\text { of saying and/or major grammatical and lexical errors }\end{array}$ \\
\hline 0 & Cannot evaluate & The utterance is impossible to understand \\
\hline
\end{tabular}

Adopted from Taguchi (2013) 
The degree of agreement between the ratings assigned by the two native speakers of English was then assessed through Cohen's Kappa which is a measure of inter-rater reliability used to measure agreement between two coders (Saldanha \& O'Brien, 2014). The analysis of Cohen's Kappa would give a value between -1 and +1 . The interpretation of the values obtained through Cohen's Kappa, according to Landis and Koch (1977), are presented in Table 2. The inter-rater reliability assessed for the responses to the discourse completion task was 0.88 which according to the guidelines set by Landis and Koch (1977) indicates an almost perfect agreement between the two raters. For cases which received different ratings, the two native speakers of English discussed until they reached an agreement.

Table 2. Interpretation of Cohen's Kappa Values

\begin{tabular}{ll}
\hline Values & Interpretation \\
\hline Smaller than 0.00 & Poor Agreement \\
\hline 0.00 to 0.20 & Slight Agreement \\
\hline 0.21 to 0.40 & Fair Agreement \\
\hline 0.41 to 0.60 & Moderate Agreement \\
\hline 0.61 to 0.80 & Substantial Agreement \\
\hline 0.81 to 1.00 & Almost Perfect Agreement \\
\hline
\end{tabular}

To assess the relationship between attitude toward cultural instruction and pragmatic comprehension ability as well as attitude toward cultural instruction and pragmatic production ability, Pearson product-moment correlation coefficient (r), which is used to describe the strength and direction of the linear relationship between two continuous variables (Gravetter \& Wallnau, 2013), was computed. Pearson correlation coefficient can only take on values from -1 to +1 . The sign out the front indicates whether there is a positive correlation (as one variable increases, so too does the other) or a negative correlation (as one variable increases, the other decreases). The size of the absolute value (ignoring the sign) provides an indication of the strength of the relationship. A perfect correlation of +1 or -1 indicates that the value of one variable can be determined exactly by knowing the value on the other variable. On the other hand, a correlation of 0 indicates no relationship between the two variables. Knowing the value on one of the variables provides no assistance in predicting the value on the second variable (Pallant, 2013). Cohen (1988) suggests a set of guidelines to interpret the values between 0.00 and 1.00. The guidelines, which have been presented in Table 3, apply whether or not there is a negative sign out the front of the $r$ value.

Table 3. Strength of Relationship

\begin{tabular}{ll}
\hline r Value & Interpretation \\
\hline $0.10-0.29$ & Small Correlation \\
\hline $0.30-0.49$ & Medium Correlation \\
\hline $0.50-1.00$ & Large Correlation \\
\hline
\end{tabular}

The squared correlation $\left(\mathrm{r}^{2}\right)$, called the coefficient of determination, was then used to measure the proportion of variability in pragmatic comprehension and pragmatic production that can be determined from their relationship with attitude toward cultural instruction. Squared correlation would give a value ranging from 0.00 to 1.00 . Cohen (1988) has also suggested a set of guidelines to interpret the values of $\mathrm{r}^{2}$. The criterion for interpreting the value of $\mathrm{r}^{2}$, as proposed by Cohen (1988), has been presented in Table 4. All the analysis was performed using Statistical Package for Social Sciences (SPSS) software, version 22.

Table 4. Percentage of Variance Explained, $\mathrm{r}^{2}$

\begin{tabular}{ll}
\hline $\mathrm{r}^{2}$ Value & Interpretation \\
\hline 0.01 & Small Correlation \\
\hline 0.09 & Medium Correlation \\
\hline 0.25 & Large Correlation \\
\hline
\end{tabular}

\section{Results}

Table 5 presents the descriptive presentation of language learners' attitudes toward cultural components of the course. Descriptive data presented in the table consists of mean, standard deviation, and frequency percentages for each specific type of attitude including affective, cognitive, and behavioral attitudes as well as the overall attitude. According to the descriptive data presented in the table, language learners' specific attitudes (affective, cognitive, and behavioral) as well 
as their overall attitudes toward cultural components of the course were positive (the mean score for all was above the cut-off of 3). In this respect, affective attitude which referred to language learners' emotional reaction to the cultural components of the course accommodated the highest mean score (mean: 4.40) and behavioral attitude which referred to their overt behavior directed toward the cultural components of the course accommodated the lowest mean score (mean: 3.80).

Table 5. Distribution of Mean Scores on the Attitude Scale

\begin{tabular}{|c|c|c|c|c|c|c|c|}
\hline \multirow[t]{2}{*}{ Scale } & \multicolumn{5}{|c|}{ Percent (\%) } & \multirow[t]{2}{*}{ Mean } & \multirow{2}{*}{$\begin{array}{l}\text { Standard } \\
\text { Deviation }\end{array}$} \\
\hline & SD & $\mathrm{D}$ & $\mathrm{N}$ & $\mathrm{A}$ & SA & & \\
\hline Affective & 0 & 0 & 6 & 48 & 46 & 4.40 & 0.34 \\
\hline Cognitive & 0 & 0 & 10 & 60 & 30 & 4.20 & 0.49 \\
\hline Behavioral & 4 & 4 & 18 & 56 & 18 & 3.80 & 0.57 \\
\hline Overall Attitude & 1.33 & 1.33 & 11.33 & 54.67 & 31.34 & 4.13 & 0.47 \\
\hline
\end{tabular}

Table 6 presents the descriptive presentation of level of pragmatic comprehension of language learners participating in the study. Descriptive data presented in the table consists of the number and percentage of participants in each level of pragmatic comprehension. According to the descriptive data, the majority of participants exhibited a low level of pragmatic comprehension ability being positioned at the poor and weak levels of pragmatic comprehension ( 88 percent) whereas very few of them exhibited a moderate level of pragmatic comprehension being positioned at the strong level of pragmatic comprehension (12 percent). None of the participants, however, managed to exhibit an optimal level of pragmatic comprehension ability.

Table 6. Descriptive Presentation of Levels of Pragmatic Comprehension

\begin{tabular}{lcc}
\hline Levels of Pragmatic Comprehension & Number of Participants & Percentage of Participants \\
\hline Poor Pragmatic Comprehension & 8 & 16 \\
\hline Weak Pragmatic Comprehension & 36 & 72 \\
\hline Strong Pragmatic Comprehension & 6 & 12 \\
\hline Optimal Pragmatic Comprehension & 0 & 0 \\
\hline
\end{tabular}

Table 7 presents the descriptive presentation of level of pragmatic production of language learners participating in the study. Descriptive data presented in the table consists of the number and percentage of participants in each level of pragmatic production. According to the descriptive data, the majority of participants presented their pragmatic production ability at a satisfactory level (76 percent). As the data shows, none of the participants presented pragmatic production ability at a 'cannot evaluate' level, 24 percent of participants presented their pragmatic production ability at a low level ('obviously off' level), 64 percent of participants presented their pragmatic production ability at an acceptable level ('slightly off, but acceptable' level), and 12 percent of participants presented their pragmatic production ability at a high level ('native-like' level).

Table 7. Descriptive Presentation of Levels of Pragmatic Production

\begin{tabular}{lcc}
\hline Levels of Pragmatic Production & Number of Participants & Percentage of Participants \\
\hline Cannot evaluate & 0 & 0 \\
\hline Obviously off & 12 & 24 \\
\hline Slightly off, but acceptable & 32 & 64 \\
\hline Native-like & 6 & 12 \\
\hline
\end{tabular}

Table 8 presents the results of Pearson product-moment correlation coefficient (r) analysis for language learners' level of attitudes toward cultural instruction and their pragmatic comprehension ability. The first thing to consider in correlation analysis is the direction of the relationship between the variables (attitude toward cultural instruction and pragmatic comprehension ability). The data shows that there is a positive relationship between the two variables, that is, the higher the attitude toward cultural instruction the higher the pragmatic comprehension ability. The second thing to consider in correlation analysis is the size of the value of the correlation coefficient. This value will indicate the strength of the relationship between the two variables (attitude toward cultural instruction and pragmatic comprehension ability). 
The value of correlation coefficient obtained in the analysis of Pearson product-moment correlation coefficient ( $r$ ) is 0.752 which according to the guidelines proposed by Cohen (1988) to interpret the values of correlation coefficient suggests quite a strong relationship between attitude toward cultural instruction and pragmatic comprehension ability.

Table 8. Correlation between Attitude toward Cultural Instruction and Pragmatic Comprehension Ability

\begin{tabular}{|c|c|c|c|}
\hline & & Overall Attitude & Pragmatic Comprehension \\
\hline \multirow[t]{3}{*}{ Overall Attitude } & Pearson Correlation & 1 & $0.752 * *$ \\
\hline & Sig. (2-tailed) & & 0.000 \\
\hline & $\mathrm{N}$ & 50 & 50 \\
\hline \multirow[t]{3}{*}{ Pragmatic Comprehension } & Pearson Correlation & $0.752 * *$ & 1 \\
\hline & Sig. (2-tailed) & 0.000 & \\
\hline & $\mathrm{N}$ & 50 & 50 \\
\hline
\end{tabular}

To get an idea of how much variance the two variables (attitude toward cultural instruction and pragmatic comprehension ability) share, the coefficient of determination was calculated. This can be obtained by squaring the correlation value. The coefficient of determination for the obtained correlation analysis is $\mathrm{r}^{2}=(0.752)^{2}=0.5655$ which according to the guidelines proposed by Cohen (1988) to interpret the values of coefficient of determination suggests a very large correlation coefficient. To convert the value of coefficient of determination to percentage of variance, it was multiplied by 100 , that is, $\mathrm{r}^{2}=(0.752)^{2} \times 100=56.55$. This suggests that attitude toward cultural instruction helps to explain nearly 57 percent of the variance in language learners' pragmatic comprehension ability.

Table 9 presents the results of Pearson product-moment correlation coefficient (r) analysis for language learners' level of attitudes toward cultural instruction and their pragmatic production ability. The first thing to consider in correlation analysis is the direction of the relationship between the variables (attitude toward cultural instruction and pragmatic production ability). The data shows that there is a positive relationship between the two variables, that is, the higher the attitude toward cultural instruction the higher the pragmatic production ability. The second thing to consider in correlation analysis is the size of the value of the correlation coefficient. This value will indicate the strength of the relationship between the two variables (attitude toward cultural instruction and pragmatic production ability). The value of correlation coefficient obtained in the analysis of Pearson product-moment correlation coefficient (r) is 0.852 which according to the guidelines proposed by Cohen (1988) to interpret the values of correlation coefficient suggests quite a strong relationship between attitude toward cultural instruction and pragmatic production ability.

Table 9. Correlation between Attitude toward Cultural Instruction and Pragmatic Production Ability

\begin{tabular}{llcc}
\hline & & Overall Attitude & Pragmatic Production \\
\hline \multirow{2}{*}{ Overall Attitude } & \multicolumn{1}{l}{ Pearson Correlation } & 1 & $0.852^{* *}$ \\
\cline { 2 - 4 } & Sig. (2-tailed) & & 0.000 \\
\cline { 2 - 4 } & $\mathrm{N}$ & 50 & 50 \\
\hline Pragmatic Production & Pearson Correlation & $0.852^{* *}$ & 1 \\
\cline { 2 - 4 } & Sig. (2-tailed) & 0.000 & 50 \\
\cline { 2 - 4 } & $\mathrm{N}$ & 50 & 50 \\
\hline
\end{tabular}

**. Correlation is significant at the 0.01 level (2-tailed).

To get an idea of how much variance the two variables (attitude toward cultural instruction and pragmatic production ability) share, the coefficient of determination was calculated. This can be obtained by squaring the correlation value. The coefficient of determination for the obtained correlation analysis is $r^{2}=(0.852)^{2}=0.7259$ which according to the guidelines proposed by Cohen (1988) to interpret the values of coefficient of determination suggests a very large correlation coefficient. To convert the value of coefficient of determination to percentage of variance, it was multiplied by 100 , that is, $r^{2}=(0.852)^{2} \times 100=72.59$. This suggests that attitude toward cultural instruction helps to explain nearly 73 percent of the variance in language learners' pragmatic production ability.

\section{Discussion}

The study found that although there was a strong positive relationship between attitude toward cultural instruction and pragmatic comprehension ability as well as attitude toward cultural instruction and pragmatic production ability, the correlation between attitude toward cultural instruction and pragmatic production ability was stronger than the correlation between attitude toward cultural instruction and pragmatic comprehension ability. Language learners who possessed a more positive attitude toward cultural component of the course exhibited a higher pragmatic comprehension ability and pragmatic production ability than language learners who possessed a more negative attitude toward cultural components of the course. Therefore, both null hypotheses of the study which state that there is no significant 
relationship between language learners' attitudes toward cultural instruction and their pragmatic comprehension ability and there is no significant relationship between language learners' attitudes toward cultural instruction and their pragmatic production ability are rejected.

These findings can be explained through noticing hypothesis. Noticing is a crucial cognitive construct in target language acquisition. "The orthodox position in psychology is that there is little if any learning without attention" (Schmidt, 2001:11). Noticing hypothesis states that "people learn about the things that they attend to and do not learn much about the things they do not attend to" (Schmidt, 2001:30). In order for the input to become intake, the detection of input in the form of awareness and attention is necessary (Schmidt, 1995). Not all input has equal value and only that input which is noticed then becomes available for intake and effective processing (Schmidt, 1990; 2001). Intake is part of the input which is being paid attention to and is taken into short-term memory and consequently is integrated into the interlanguage, a language independent from both the language learner's native language and the target language (Selinker, 1972).

In the current study, language learners who were more interested in the cultural components of the course definitely directed their noticing and attention to the pragmalinguistic and sociopragmatic features of the target language. This noticing of target language pragmatic features certainly helped the input they received to be turned into intake and the consequent development of their pragmatic competence needed for a successful cross-cultural communication. However, pragmalinguistic and sociopragmatic features of the target language definitely went unnoticed for language learners who were less interested in cultural components of the course resulting in their insufficient knowledge of pragmatic features of the target language to equip them with the ability to comprehend and produce target language expressions according to the pragmalinguistic and sociopragmatic norms of the target language.

The findings obtained in the current study are in line with the findings obtained in the studies conducted by Albirini (2009), Saricoban and Caliskan (2011), Rafieyan et al. (2013a; 2013b), and Dweik and Al-sayyed (2015) whose studies revealed the positive attitudes of language learners toward learning the cultural elements of the target language community. The findings obtained in the current study are also consistent with the findings obtained in the study conducted by Rafieyan et al. (2013b) who found that a positive attitude toward the learning of the cultural features of the target language community increases language learners' ability to comprehend pragmatically implied meanings of target language expressions.

\section{Conclusion}

The study revealed a strong positive relationship between attitude toward cultural instruction and pragmatic comprehension ability as well as attitude toward cultural instruction and pragmatic production ability. Language learners who were more interested in learning the cultural features of the target language community exhibited a better knowledge of target language pragmatic comprehension and pragmatic production than language learners who did not show a positive attitude toward learning the cultural components of the target language community. Therefore, language instructors are advised to incorporate interesting cultural features of the target language community in language classes and present them in interesting ways to attract language learners' attention and interest (Rafieyan et al., 2013c; Rafieyan et al., in press).

The study was limited in some ways, however. First of all, the study merely followed a cross-sectional design and did not adopt an experimental pretest/posttest design to examine the effect of cultural intervention on the development of language learners' pragmatic competence with respect to their attitudes toward cultural instruction. Secondly, the study did not consider the significant role of language learners' level of cultural intelligence in the development of their pragmatic competence as a high level of cultural intelligence enables them to function and manage effectively in culturally diverse settings (Earley \& Ang, 2003). Therefore, future studies are recommended to follow an experimental design to investigate the effect of cultural intervention in the development of pragmatic competence with respect to the role of cultural intelligence and attitude toward cultural instruction.

\section{Acknowledgements}

The author would like to acknowledge the contribution of Ali Rafieyan.

\section{References}

Albirini, A. (2009). Using Technology, Literature and Guest Speakers to Raise the Cultural Awareness of Arabic Language Learners. The International Journal of Language Society and Culture, 28, 1-15.

Bachman, L. F. (1990). Fundamental Considerations in Language Testing. Oxford: Oxford University Press.

Bardovi-Harlig, K. (2001). Empirical Evidence of the Need for Instruction in Pragmatics. In K. R. Rose, \& G. Kasper (Eds.), Pragmatics in Language Teaching (pp. 13-32). Cambridge: Cambridge University Press. http://dx.doi.org/10.1017/CBO9781139524797.005

Bardovi-Harlig, K., \& Dornyei, B. (1998). Do Language Learners Recognize Pragmatic Violations? Pragmatic versus Grammatical Awareness in Instructed L2 Learning. TESOL Quarterly, 32(2), 233-259. http://dx.doi.org/10.2307/3587583

Bardovi-Harlig, K. (2009). Conventional Expressions as a Pragmalinguistic Resource: Recognition and Production of 
Conventional Expressions in L2 Pragmatics. Language Learning, 59(4), 755-795. http://dx.doi.org/10.1111/j.14679922.2009.00525.X

Barron, A. (2003). Acquisition in Interlanguage Pragmatics: Learning How to Do Things with Words in a Study Abroad Context. Amesterdam: Benjamins. http://dx.doi.org/10.1075/pbns.108

Cohen, J. A. (1988). Statistical Power Analysis for the Behavioral Sciences. Hillsdale, NJ: Lawrence Erlbaum Associates.

Dweik, B. S., \& Al-sayyed, S. W. (2015). Attitudes of Jordanian Students, Teachers and Educationalists towards Including Culture in EFL Classes and Textbooks “Action Pack 12". International Journal of Social Sciences, 40(1), 1126-1141.

Earley, P. C., \& Ang, S. (2003). Cultural Intelligence: Individual Interactions across Cultures. Palo Alto, Calif: Stanford University Press.

Gharaghani, Z., Eslami Rasekh, A., Dabaghi, A., \& Tohidian, I. (2011). Effect of Gender on Politeness Strategies in Greetings of Native Speakers of Persian; English and EFL Learners. Cypriot Journal of Educational Sciences, 3, 93-117. Gravetter, F. J., \& Wallnau, L. B. (2013). Statistics for the Behavioral Sciences. Belmont, C A: Wadsworth Publishing.

Kasper, G., \& Rose, K. (2002). The Role of Instruction in Learning Second Language Pragmatics. Language Learning, 52(Supplement 1), 237-273. http://dx.doi.org/10.1111/j.1467-1770.2002.tb00028.x

Landis, J. R., \& Koch, G. G. (1977). The Measurement of Observer Agreement for Categorical Data. Biometrics, 33(1), 159-174. http://dx.doi.org/10.2307/2529310

Liu, J. (2006). Measuring Interlanguage Pragmatic Knowledge of EFL Learners. Frankfurtam Main: Peter Lang.

Pallant, J. (2013). SPSS Survival Manual: A Step by Step Guide to Data Analysis Using SPSS Program (5th ed.). Australia: Allen \& Unwin.

Rafieyan, V., Lin, S. E., \& Abdul-Rashid, M. (2013a). Language Learners' Attitudes towards the Incorporation of Target Language Culture into Foreign Language Instructions. International Journal of Linguistics, 5(4), 169-177. http://dx.doi.org/10.5296/ijl.v5i4.4193

Rafieyan, V., Norazman, A. M., \& Lin, S. E. (2013b). Relationship between Attitude toward Target Language Culture Instruction and Pragmatic Comprehension Development. English Language Teaching, 6(8), 125-132. http://dx.doi.org/10.5539/elt.v6n8p125

Rafieyan, V., Lin, S. E., \& Abdul Rashid Mohamed. (2013c). The Effect of Integrative Attitude on the Development of Pragmatic Comprehension. Elixir Social Studies, 57, 14041-14045.

Rafieyan, V., Mahmoudi, E., \& Adlina, A. S. (in press). Relationship between Attitude toward Cultural Instruction and Translation of Culture-Bound Texts.

Ran, L. (2007). The Relationship between Linguistic Proficiency and Pragmatic Ability. US-China Foreign Language, 5 , 13-17.

Rose, K. R. (2005). On the Effects of Instruction in Second Language Pragmatics. System, 33(3), 385-399. http://dx.doi.org/10.1016/j.system.2005.06.003

Saldanha, G., \& O’Brien, S. (2014). Research Methodologies in Translation Studies. New Tork, NY: Routledge.

Saricoban, A., \& Caliskan, G. (2011). The Influence of Target Culture on Language Learners. Journal of Language and Linguistic Studies, 7(1), 7-17.

Schmidt, R. W. (1990). The Role of Consciousness in Second Language Learning. Applied Linguistics, 11(2), 129-158. http://dx.doi.org/10.1093/applin/11.2.129

Schmidt, R. W. (1995). Consciousness and Foreign Language Learning: A Tutorial on the Role of Attention and Awareness in Learning. In R. W. Schmidt (Ed.), Attention and Awareness in Foreign Language Learning (Technical Report No. 9, pp. 1-63). University of Hawaii: Honolulu.

Schmidt, R. W. (2001). Attention. In P. Robinson (Ed.), Cognition and Second Language Instruction (pp. 3-32). Cambridge: Cambridge University Press. http://dx.doi.org/10.1017/CBO9781139524780.003

Selinker, L. (1972). Interlanguage. International Review of Applied Linguistics, 10(2), 209-230. http://dx.doi.org/10.1515/iral.1972.10.1-4.209

Taguchi, N. (2007). Development of Speed and Accuracy in Pragmatic Comprehension in English as a Foreign Language. TESOL Quarterly, 42, 313-338. http://dx.doi.org/10.1002/j.1545-7249.2007.tb00061.x

Taguchi, N. (2008). The Role of Learning Environment in the Development of Pragmatic Comprehension: A Comparison of Gains between EFL and ESL Learners. Studies in Second Language Acquisition, 30, 423-452. http://dx.doi.org/10.1017/S0272263108080716

Taguchi, N. (2013). Comprehension of Conversational Implicature in L2 Chinese. Pragmatics \& Cognition, 21(1), 139157. http://dx.doi.org/10.1075/pc.21.1.06tag

Thomas, J. (1995). Meaning in Interaction: An Introduction to Pragmatics. London: Longman.

Zimbardo, P., Ebbesen, E., \& Maslach, C. (1977).Influencing Attitudes and Changing Behavior. Addison-Wesley Publishing Company. 